\title{
Correlation of maximal respiratory exchange ratio with anaerobic power and maximal oxygen uptake in anaerobic trained athletes
}

Selcen Korkmaz Eryılmaz ${ }^{1 \mathrm{ABCD}}$, Metin Polat ${ }^{2 \mathrm{ABD}}$

${ }^{1}$ Faculty of Sport Science, Cukurova University, Turkey ${ }^{2}$

Faculty of Sport Science, Sivas Cumhuriyet University, Turkey

Authors' Contribution: A - Study design; B - Data collection; C - Statistical analysis; D - Manuscript Preparation; E - Funds Collection.

\author{
Abstract \\ Background \\ and Study Aim
}

Material and Methods

Results

Conclusions

Keywords:
The respiratory exchange ratio (RER) is the ratio of the amount of carbon dioxide produced (VCO2) to the amount of oxygen uptake (VO2) is important. It indirectly informs about the predominant metabolic pathway to provide the energy needed during exercise. The relationship of maximal RER with aerobic and anaerobic capacity in athletes remains unclear. The purpose of this study was to investigate the relationship between maximal RER and anaerobic power and maximal oxygen uptake $\left(\mathrm{VO}_{2 \max }\right)$ in anaerobic trained athletes.

Thirteen male alpine skiers (age $18.1 \pm 3.1$ years) competing in national and international competitions participated in the study. Athletes first performed an incremental treadmill run test to determine their $\mathrm{VO}_{2 \max }(\mathrm{ml} / \mathrm{kg} / \mathrm{min})$, maximal RER $\left(\mathrm{VCO}_{2} / \mathrm{VO}_{2}\right)$ and maximal running speed $(\mathrm{km} / \mathrm{h})$. After 48 hours, the athletes performed the Wingate anaerobic test to determine peak power, mean power, minimum power, and fatigue index. Pearson correlation coefficients were used to examine the relations between variables. Maximal RER was positively correlated with peak power $(r=0.587, p<0.035)$, mean power $(r=0.656$, $p<0.015)$ and minimum power $(r=0.674, p<0.012)$. Maximal RER did not significantly correlate with fatigue index $(p>0.05)$. Maximal RER was negatively correlated with the $\mathrm{VO}_{2 \max }(r=-0.705, p<0.007)$ and maximal running speed $(r=-0.687, p<0.01)$.

Maximal RER may be useful for evaluating anaerobic capacity in anaerobic-trained athletes. Measuring the maximal RER values of athletes during incremental exercise may provide information about physiological adaptations in response to physical training. anaerobic capacity, aerobic capacity, wingate test, incremental exercise

\section{Introduction}

The ratio of carbon dioxide produced $\left(\mathrm{VCO}_{2}\right)$ to the amount of oxygen $\left(\mathrm{VO}_{2}\right)$ used is known as the respiratory exchange ratio (RER). In addition to blood lactic acid, the RER is widely used to assess physiological metabolism in athletes [1]. The RER indirectly informs about the predominant metabolic pathway to provide the energy needed during exercise [2].

The RER changes depending on whether the exercise intensity is above or below the anaerobic threshold and increases with exercise intensity [3, 4]. RER values less than 1.00 mean that energy requirement meets predominantly by aerobic metabolism during exercise. Steady-state RER values measured at rest and exercise intensities below the anaerobic threshold typically range from 0.7 to 1.0 , depending on the ratio of substrate utilization to obtain energy [3,5]. A high RER value indicates predominantly carbohydrate utilization, while a low RER value indicates lipid oxidation $[3,6]$.

A RER value of about 1.00 represents the highest exercise intensity at which the respiratory system maintains a physiological steady state [7]. Lactic acid produced as a result of the anaerobic glycolysis during exercise disassociates into lactate and hydrogen ions $\left(\mathrm{H}^{+}\right)$, and $\mathrm{H}^{+}$is buffered by both bicarbonate and nonbicarbonate buffers [8]. The relationship between $\mathrm{VCO}_{2}$

\footnotetext{
(c) Selcen Korkmaz Eryılmaz, Metin Polat, 2021

doi:10.15561/26649837.2021.0408
}

and $\mathrm{VO}_{2}$ during an incremental exercise is characterized by a relatively linear relationship up to a certain intensity of exercise $[9,10]$. When anaerobic glycolysis begins to predominate energy production, $\mathrm{VCO}_{2}$ increases faster than $\mathrm{VO}_{2}$, resulting in an increase in $\operatorname{RER}[10,11]$. The RER value rises above 1.00 due to non-metabolic $\mathrm{CO}_{2}$ production from buffering of excess $\mathrm{H}^{+}$with bicarbonate in addition to the $\mathrm{CO}_{2}$ produced by aerobic metabolism $[11,12]$. At exercise intensities above the anaerobic threshold (RER > 1.00), hyperventilation occurs so that additional $\mathrm{CO}_{2}$ produced by buffering excess $\mathrm{H}^{+}$can be removed from the body $[10,11]$. Therefore, a RER value above 1.00 during exercise indicates predominantly anaerobic metabolism is utilized [11, 12].

RER is used as one of the simplest non-invasive methods to determine the anaerobic threshold [13]. The RER method used to assess the anaerobic threshold is based on the observation that a part of the expired $\mathrm{CO}_{2}$ is derived from the body bicarbonate pool because of lactic acid accumulation during exercise [10]. Anaerobic threshold values based on RER have been shown to be associated with athletic performance $[14,15]$. RER has been shown to provide information about physical fitness at exercise intensity above the anaerobic threshold in trained and untrained healthy men [3]. RER values are also used to provide an index of whether the exercise intensity is too high to be sustained throughout the exercise [16]. A RER value above 1.10 is considered a 
good indicator of achieving maximum effort in healthy individuals [16-18]. During incremental exercise, RER can provide a prediction of maximal oxygen uptake $\left(\mathrm{VO}_{2 \max }\right)$ in untrained and trained individual [19]. The peak RER can also be used to assess exercise capacity and metabolic responses in individuals with reduced exercise tolerance [20].

Considering that the RER exceeds 1.0 at exercise intensities above the anaerobic threshold, it has been interpreted that high RER values may be important in high-intensity short-distance efforts $[9,15]$. During highintensity exercise, blood lactate concentration has been shown to be the most important determinant of RER in athletes [21]. Blood lactate concentration can be used to estimate aerobic and anaerobic capacity as it reflects the balance between lactate production and removal [8]. It has been shown that there is a significant relationship between anaerobic performance and post-exercise lactate concentration $[22,23]$. The increase in $\mathrm{CO}_{2}$ and thus the RER has been found to be quantitatively related to the magnitude of the increase in lactic acid [12]. Therefore, the maximal RER measured during incremental exercise may be related to anaerobic capacity in athletes.

The association of the maximal RER with aerobic and anaerobic capacity has not been clearly established. The purpose of this study was to investigate the relationship between maximal RER measured during incremental exercise and anaerobic power and $\mathrm{VO}_{2 \max }$ in anaerobictrained athletes.

\section{Material and Methods}

\section{Participants}

Thirteen male alpine skiers (mean $\pm \mathrm{SD}$; age 18.1 \pm 3.1 years, height $174 \pm 3.6 \mathrm{~cm}$, body mass $67 \pm 9.5$ $\mathrm{kg}$ ) competing in national and international competitions volunteered to participate in the study. Measurements were performed following the approval of the Ethics Committee and carried out in accordance with the Declaration of Helsinki. All testing and training procedures were fully explained, and written informed consent was obtained for each participant. All athletes performed two tests 48 hours apart, consisting of the incremental treadmill test and the Wingate test. To avoid unnecessary fatigue accumulation, the athletes were not allowed to perform any training the day before each test.

\section{Incremental Treadmill Test}

Incremental running test was performed on a motorized treadmill ( $\mathrm{h} / \mathrm{p} /$ Cosmos Quasar med, Nussdorf-Traunstein, Germany). Throughout all tests, breath-by-breath gas measurements were taken using an indirect calorimetric system (Quark PFT Ergo, Cosmed Srl, Rome, Italy) which was calibrated before each session to the manufacturer's instructions. The heart rate was recorded continuously using a wireless HR monitor (S610i, Polar, Finland). Breath-by-breath data were smoothed using a five-step average filter and then reduced to $15 \mathrm{~s}$ stationary averages. Maximal oxygen uptake $\left(\mathrm{VO}_{2 \max }\right)$, maximal respiratory exchange ratio (RER) and maximal running speed were determined during the incremental treadmill test.
Each athletes performed a standardized warm-up consisting of a 5-min run at their own pace followed by about 3-min stretching. Following the warm-up period, athletes performed a progressive protocol with an initial speed of $7 \mathrm{~km} / \mathrm{h}$ with speed increments of $1 \mathrm{~km} / \mathrm{h}$ at a constant 5\% incline every minute until they could no longer keep the running pace. The athletes were instructed to run until voluntary exhaustion and given strong verbal encouragement throughout the test to elicit their best performance. Achievement of $\mathrm{VO}_{2 \max }$ was considered as the attainment of at least two of the following criteria: 1) a plateau in oxygen uptake $\left(\mathrm{VO}_{2}\right)$ despite increasing speed, 2) an HR within ten beats per minute of age-predicted maximum HR (220 - age), and 3$)$ a respiratory exchange ratio (RER) above 1.10. The $\mathrm{VO}_{2 \max }$ was defined as the highest 15-s $\mathrm{VO}_{2}$ value reached during the test.

\section{Wingate Anaerobic Test}

The Wingate anaerobic test was performed on a computerized cycle ergometer (Monark 824E, Monark, Sweden) in standard version [24]. The athletes completed a warming up of 5 minutes cycling at a pedaling rate of 60-70 rpm including two unloaded maximal sprints of 5 seconds each, performed at the end of the $3 \mathrm{rd}$ and the 5 th minutes. Following the initial warm-up period, the athletes performed about 3-min stretching. The athletes were instructed to pedal as fast as possible. Following the warm-up period, the athletes pedaled at maximal (allout) effort for $30 \mathrm{~s}$ on a cycle ergometer against resistance corresponding to $7.5 \%$ of their body mass. Athletes were verbally encouraged to maintain a pedaling rate as high as possible for 30 seconds. Peak power (watts), mean power (watts), minimum power (watts) and fatigue index (percent) were calculated with Monark Anaerobic test computer software program.

\section{Statistical Analysis:}

Data are reported as the means \pm standard deviation (SD). Statistical significance was accepted at $\mathrm{p}<0.05$. The assumption of normality was assessed through the Shapiro-Wilk test. Pearson correlation coefficients were used to examine the relations between variables. Almost perfect $(r=>0.9)$, very large $(r=0.7-0.9)$, large $(r=0.5$ $0.7)$, moderate $(\mathrm{r}=0.3-0.5)$, small $(\mathrm{r}=0.1-0.3)$ or trivial $(\mathrm{r}=<0.1)$ of association were defined [25]. Simple linear regression analysis was used to determine the success of prediction (Sigma Plot 12.0, Systat Software Inc., Chicago, USA). IBM SPSS 21 software (IBM SPSS Statistics 21 Inc., Chicago, IL) was used for the statistical analyses.

\section{Results}

The results obtained during incremental treadmill test and Wingate anaerobic test are shown in Table 1. Linear regression analyses of the relationship between maximal RER and Wingate anaerobic test variables are given in figure 1.A, B and C. Maximal RER was largely positively correlated with peak power $(\mathrm{r}=0.587, \mathrm{p}<0.035)$, mean power $(\mathrm{r}=0.656, \mathrm{p}<0.015)$ and minimum power $(\mathrm{r}=$ $0.674, \mathrm{p}<0.012)$. Maximal RER did not significantly correlate with fatigue index $(\mathrm{r}=-0.074, \mathrm{p}>0.05)$. 
Figure 1.D shows the linear regression analysis of the relationship between maximal RER and $\mathrm{VO}_{2 \max }$. Maximal RER was very largely and largely negatively correlated with the $\mathrm{VO}_{2 \max }(\mathrm{r}=-0.705, \mathrm{p}<0.007)$, and maximal running speed $(r=-0.687, p<0.01)$, respectively.

Table 1. Mean values for variables determined from incremental treadmill test and Wingate anaerobic test. Mean \pm SD

\begin{tabular}{ll}
\hline Variables & Mean \pm SD \\
\hline $\mathrm{VO}_{2 \max }(\mathrm{ml} / \mathrm{kg} / \mathrm{min})$ & $54.2 \pm 6$ \\
Maximal running speed $(\mathrm{km} / \mathrm{h})$ & $14.3 \pm 0.6$ \\
Maximal RER $\left(\mathrm{CO}_{2} / \mathrm{O}_{2}\right)$ & $1.19 \pm 0.03$ \\
Peak power $($ Watts $)$ & $601.6 \pm 123.6$ \\
Mean power (Watts) & $454.9 \pm 80.1$ \\
Minimum power (Watts) & $266.8 \pm 49.9$ \\
Fatigue index $(\%)$ & $55.3 \pm 3.4$ \\
\hline
\end{tabular}

\section{Discussion}

We examined whether maximal RER measured during incremental exercise was related to anaerobic power and $\mathrm{VO}_{2 \max }$ in anaerobic-trained athletes. The main results of this study indicated that maximal RER was positively correlated with the peak power, mean power and minimum power. This finding suggests that the higher the maximal RER, the better the anaerobic capacity in anaerobictrained athletes. In addition, higher maximal RER was associated with lower $\mathrm{VO}_{2 \max }$ and maximal running speed during the incremental exercise. Maximal RER may be useful for estimating anaerobic capacity in anaerobictrained athletes.

Above the anaerobic threshold, RER kinetics reflect additional $\mathrm{CO}_{2}$ production as a result of $\mathrm{H}^{+}$buffering associated with lactic acid increase and compensatory hyperventilation for metabolic acidosis [9, 11]. The association between increased blood lactate concentration and decrease in intracellular $\mathrm{pH}$ [26] has been documented to occur with a decrease in power [27]. A peak RER value between 1.10 and 1.20 is considered a good indicator of achieving maximum effort in healthy individuals during incremental exercise [17]. In the present study, the maximal RER measured during incremental exercise was related to the peak power, mean power and minimum power of the Wingate anaerobic test. Anaerobic power and capacity are the best indicator of athletic performance in alpine skiing, which race duration varies between 45 seconds and 3 minutes [28]. Anaerobic capacity in alpine skiing is commonly evaluate using the Wingate
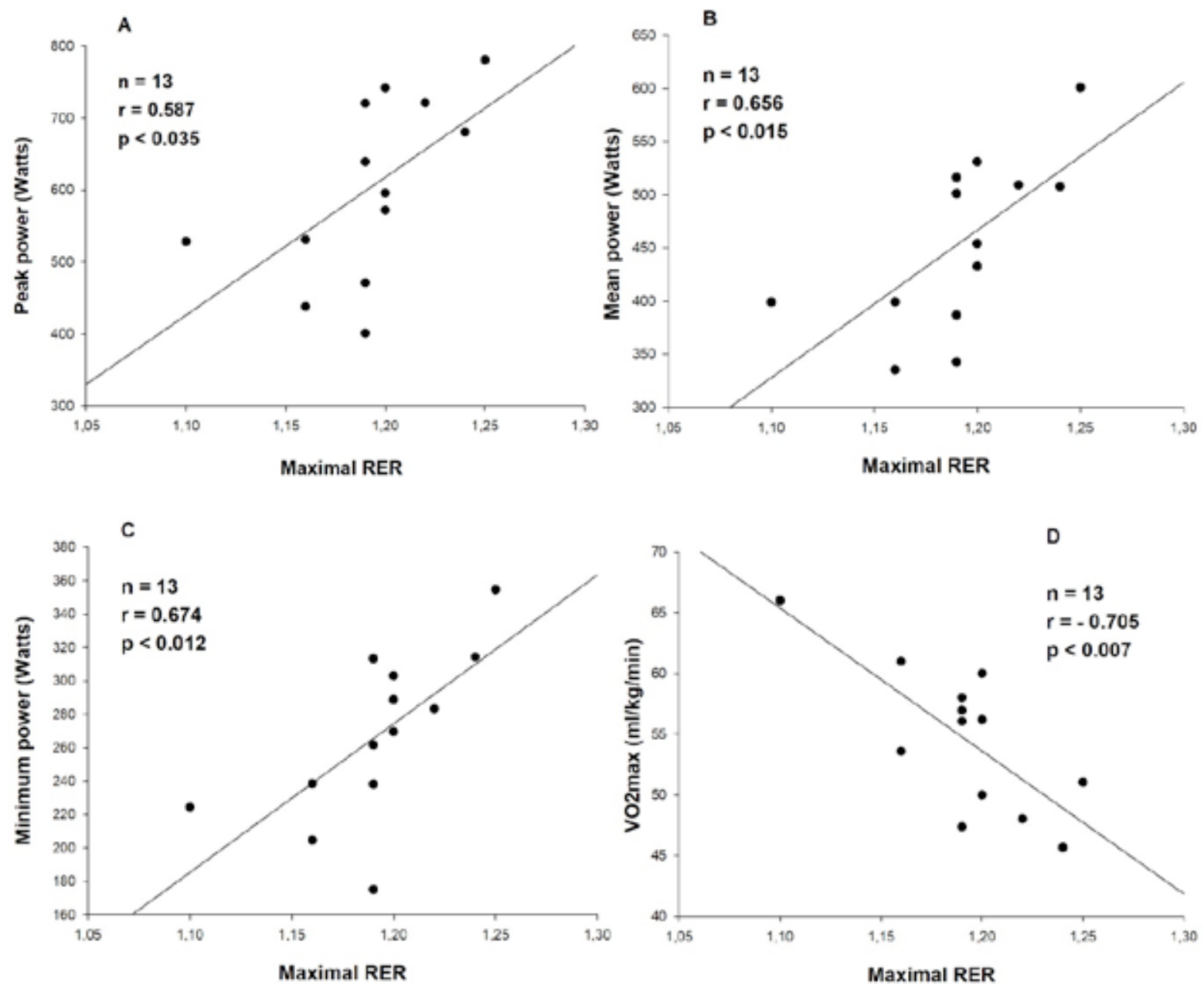

Figure 1. Correlation between A) peak power and maximal RER, B) mean power and maximal RER, C) minimum power and maximal RER, and D) $\mathrm{VO}_{2 \max }$ and maximal RER in all subjects. 
anaerobic test $[29,30]$. The Wingate anaerobic test, consisting of 30 seconds of maximum cycle exercise, is performed to determine the athletes' ability to maintain their maximal anaerobic power and high-power output [31]. It has been shown that $80 \%$ of the energy turnover during Wingate anaerobic test is derived from anaerobic metabolism dominated by glycolysis [33]. Maximal RER may be useful for determining the glycolytic capacity in anaerobic trained athletes. We did not directly measure blood lactate levels in our study. On the other hand, the maximal RER is likely to reflect the rate of lactic acid accumulation [12]. During high-intensity exercise at $70 \%$ of peak power output $\left(80 \% \mathrm{VO}_{2 \text { peak }}\right)$, plasma lactate concentration has been shown to be the most important determinant of RER in trained cyclists [21]. The higher RER value may be explained by the higher demand of anaerobic glycolysis during the incremental exercise test and thus the higher lactic acid concentration. It has been shown that the subjects who achieved the best performance in the repeated sprint test were achieved higher lactate concentrations [22]. A close correlation has been found to be between the post-competition blood lactate concentration and the velocity maintained over 400-m and 800-m top-level competitions [23]. Besides the post-exercise blood lactate concentration [23], maximal RER values may also be used to evaluate the anaerobic capacity of athletes.

A RER value above 1.10 has been proposed as evidence of attainment of $\mathrm{VO}_{2 \max }$, which is known as an indicator of aerobic capacity $[17,18]$. In the current study, maximal RER was statistically negatively related to $\mathrm{VO}_{2 \max }$ and maximal running speed measured during the incremental exercise. Similar to our results, Ramos-Jiménez et al. showed that $\mathrm{VO}_{2 \max }$ was negatively correlated with RER measured during three different exercises at below, within, or above the lactate threshold [3]. A negative correlation between relative blood lactate change and $\mathrm{VO}_{2 \max }$ during incremental exercise has been reported [8]. RER response during maximal incremental exercise may be affected by different types of physical training [19]. In our study, the subject profile consists of alpine skiers. In alpine skiing, the physical capacity of the athlete is closely related to the ability to perform high-intensity exercise and develop high power output [30]. For this reason, the traditional training of alpine skiers includes anaerobic exercises such as plyometric training, speed, change of direction and resistance training [33]. During incremental exercise, anaerobic-trained athletes have been shown to have a greater lactate increase after the anaerobic threshold than endurance-trained athletes, despite having lower $\mathrm{VO}_{2 \mathrm{~m}}$ [8]. In our previous study, we observed higher maximal RER values in alpine skiers compared to endurance athletes, despite a lower $\mathrm{VO}_{2 \max }$ and shorter running time to exhaustion during incremental exercise [34]. Higher RER values may mean that anaerobic-trained athletes utilized a greater proportion of anaerobic metabolism at higher intensity during exercise than aerobic-trained athletes. Anaerobic training increases intracellular and extracellular buffer capacity [35], which may contribute to a higher increase in RER values [36].

Maximal RER values may also be related to the genetic makeup of the athlete. Fast-twitch fiber-dominant muscle has a higher buffering capacity of $\mathrm{H}^{+}$than slowtwitch fiber-dominant muscle [37]. RER has been shown to be inversely related to the proportion of slow-twitch muscle fibers during exercise [38]. A high RER reflects a direct respiratory response to arterial acidosis as well as an indirect stimulation of chemosensitive fibers by local metabolic changes [16]. When the buffering systems are saturated, $\mathrm{H}^{+}$can no longer be compensated by the circulation, causing a drop in blood $\mathrm{pH}$ and, as a result, the accumulation of $\mathrm{H}^{+}$stimulates hyperventilation [8, 11]. A high muscle buffer capacity may allow anaerobic glycolysis to be longer utilization before the performancelimiting $\mathrm{pH}$ level is reached [37].

After the anaerobic training period, blood lactate concentrations may increase more than before the training period during exhaustive exercise due to increased muscle buffer capacity and glycolytic enzymes [39]. It has been shown that athletes who regularly perform anaerobic training have a greater muscle buffering capacity than endurance athletes or untrained subjects [8]. During anaerobic exercise training, large accumulation of lactic acid may improve buffer capacity $[35,39]$, providing a stimulus for the adaptation of muscle $\mathrm{pH}$ regulatory systems [31]. Reducing the inhibitory effects of $\mathrm{H}^{+}$in muscle cells by anaerobic training may lead to the improvement of the athlete's ability to perform high-intensity exercise for a longer period [31]. The magnitude of the RER increase at heavy exercise intensities is likely to depend on the rate of buffering [12]. After a period of anaerobic training, the $\mathrm{H}^{+}$release and buffering capacity of the muscles has been shown to be increases [40]. In our previous study, after a 6-week period of anaerobic training, maximal RER values during incremental exercise increased by $5.6 \%$ compared to the pre-training period, which may be due to enhanced buffering capacity [36]. On the other hand, endurance training to improve aerobic capacity increases oxidative enzyme activity while decreasing RER values [41]. Presumably, the anaerobic training stimulus may increase glycolytic and buffering capacity as contributing factor to anaerobic capacity. Therefore, it is likely that RER during incremental exercise may increase in relation to anaerobic capacity in anaerobic-trained athletes.

\section{Conclusions}

The results of the present study indicated that higher maximal RER was associated with higher anaerobic power, while lower aerobic capacity in anaerobic-trained athletes. Maximal RER may be important for determining anaerobic capacity in anaerobic-trained athletes. Measuring the maximal RER values of athletes during incremental exercise may help evaluate their physiological characteristics and physiological adaptations in response to physical training. Further research is necessary to determine the relationship between anaerobic capacity and maximal RER and lactate concentration in athletes. 


\section{Financial Support}

The authors did not receive financial support for the research of this study.

\section{Conflict of interest}

Authors declare no conflict of interest.

\section{References}

1. $\mathrm{Xu} \mathrm{G}, \mathrm{Ye} \mathrm{Y}$. Correlations between oxy-hemoglobin and respiratory exchange ratio in the quadriceps during the early phase of exercises. Journal of Innovative Optical Health Sciences, 2010; 3(02), 141-146. https://doi.org/10.1142/S1793545810000885

2. Nelson, MT, Biltz, GR, Dengel DR. Repeatability of respiratory exchange ratio time series analysis. Journal of Strength and Conditioning Research, 2015;29(9): 2550-2558. https://doi.org/10.1519/JSC.0000000000000924

3. Ramos-Jiménez A, Hernández-Torres RP, Torres-Durán PV, Romero-Gonzalez J, Mascher D, Posadas-Romero $\mathrm{C}$, et al. The respiratory exchange ratio is associated with fitness indicators both in trained and untrained men: a possible application for people with reduced exercise tolerance. Clinical Medicine Circulatory, Respiratory and Pulmonary Medicine, 2008; 2: CCRPM-S449. https://doi.org/10.4137/CCRPM.S449

4. Stringier W, Wasserman K. Casaburi R. TheVCO $/ \mathrm{VO}_{2}$ relationship during heavy, constant work rate exercise reflects therateoflacticacidaccumulation.EuropeanJournalofApplied Physiology and Occupational physiology, 1995; 72(1):25-31. https://doi.org/10.1007/BF00964110

5. Toda K, Oshida Y, Tokudome M., Manzai T, Sato Y. Effects on Moderate Exercise on Metabolic Responses and Respiratory Exchange Ratio (PER). Nagoya Journal of Medical Science, 2002; 65(3-4): 109-113.

6. Pendergast DR, Leddy JJ, Venkatraman JT. A perspective on fat intake in athletes. Journal of the American College of Nutrition, 2000; 19(3): 345-350. https://doi.org/10.1080/07315724.2000.10718930

7. Zagatto AM, Miyagi WE, Sakugawa RL, Kaminagakura EI, Papoti M. Aerobic Endurance Measurement by Respiratory Exchange Ratio during a Cycle Ergometer Graded Exercise Test. Journal of Exercise Physiology Online, 2012; 15(5): 49-56.

8. Hasanli M, Nikooie R, Aveseh M, Mohammad F. Prediction of aerobic and anaerobic capacities of elite cyclists from changes in lactate during isocapnic buffering phase. Journal of Strength and Conditioning Research, 2015; 29(2): 321-329. https://doi.org/10.1519/JSC.0000000000000640

9. Whipp BJ. Physiological mechanisms dissociating pulmonary $\mathrm{CO} 2$ and $\mathrm{O} 2$ exchange dynamics during exercise in humans. Experimental Physiology, 2007; 92(2): 347-355. https://doi.org/10.1113/expphysiol.2006.034363

10.Beaver WL, Wasserman K, Whipp BJ. A new method for detecting the anaerobic threshold by gas exchange. Journal of applied physiology, 1986; 60(6): 2020-2027. https://doi.org/10.1152/jappl.1986.60.6.2020

11. Wasserman K, Hansen J, Sue D, Stringer W, Whipp B. Principles of exercise testing and interpretation. 4th ed. Philadelphia: Lippincott Williams and Wilkins; 2004.

12.Stringer W, Wasserman K, Casaburi R. The VCO2/ VO2 relationship during heavy, constant work rate exercise reflects the rate of lactic acid accumulation. European Journal of Applied Physiology and Occupational Physiology, 1995;72(1-2): 25-31. https://doi.org/10.1007/BF00964110

13.Solberg G, Robstad B, Skjønsberg OH, Borchsenius F. Respiratory gas exchange indices for estimating the anaerobic threshold. Journal of Sports Science \& Medicine, 2005; 4(1): 29-36.

14.Gilenstam KM, Thorsen K, Henriksson-Larsén KB. Physiological correlates of skating performance in women's and men's ice hockey. Journal of Strength and Conditioning Research, 2011; 25(8): 2133-2142. https://doi.org/10.1519/JSC.0b013e3181ecd072

15.Bellar D, Judge LW. Modeling and relationship of respiratory exchange ratio to athletic performance. Journal of Strength and Conditioning Research, 2012; 26(9): 2484-2489. https://doi.org/10.1519/JSC.0b013e31823f271d

16.Shephard RJ. Respiratory gas exchange ratio and prediction of aerobic power. Journal of Applied Physiology, 1975; 38(3): 402-406. https://doi.org/10.1152/jappl.1975.38.3.402

17.Balady GJ, Berra KA, Golding LA. Interpretation of clinical test data. In: Franklin BA, Whaley MH, Howley ET, editors. ACSM's Guidelines for Exercise Testing and Prescription. Philadelphia: Lippincott Williams \& Wilkins; 2000. P. 11533

18.Howley ET, Bassett DR, Welch HG. Criteria for maximal oxygen uptake: review and commentary. Medicine and Science in Sports and Exercise, 1995; 27(9):1292-1301. https://doi.org/10.1249/00005768-199509000-00009

19.Aitken JC, Thompson J. The respiratory VCO2/ VO2 exchange ratio during maximum exercise and its use as a predictor of maximum oxygen uptake. European Journal of Applied Physiology and Occupational Physiology, 1988: 57(6): 714-719. https://doi.org/10.1007/BF01075993

20.Stratmann H. Effect of exercise training on multiple respiratory variables in patients with coronary artery disease: correlation with change in exercise capacity. Angiology, 1991; 42(12): 948-956. https://doi.org/10.1177/000331979104201202

21.Goedecke JH, Gibson ASC, Grobler L, Collins M, Noakes TD, Lambert EV. Determinants of the variability in respiratory exchange ratio at rest and during exercise in trained athletes. American Journal of PhysiologyEndocrinology and Metabolism, 2000;279(6): E1325-E1334. https://doi.org/10.1152/ajpendo.2000.279.6.E1325

22.Dardouri W, Selmi MA, Sassi RH, Gharbi Z, Rebhi A, Yahmed $\mathrm{MH}$, et al. Relationship between repeated sprint performance and both aerobic and anaerobic fitness. Journal of Human Kinetics, 2014; 27(40): 139-148. https://doi.org/10.2478/hukin-2014-0016

23.Lacour JR, Bouvat E. Barthélémy JC. Post-competition blood lactate concentrations as indicators of anaerobic energy expenditure during $400-\mathrm{m}$ and $800-\mathrm{m}$ races. European Journal of Applied Physiology and Occupational Physiology, 1990; 61(3): 172-176. https://doi.org/10.1007/BF00357594

24.Inbar O, Bar-Or O, Skinner J. The Wingate anaerobic test. Champaign, IL: Human Kinetics; 1996.

25.Hopkins W. A scale of magnitudes for effect statistics. In: A New View Statistics. Internet Society for Sport Science, [Internet]. 2002 [updated 2016 Jan 15; cited 2021 Jan 5]. Available from: http://www.sportsci.org/resource/stats/ effectmag.html

26.Gladden LB. Lactate metabolism: a new paradigm for the third 
millennium. The Journal of Physiology, 2004; 558(1): 5-30. https://doi.org/10.1113/jphysiol.2003.058701

27.Metzger JM, Moss RL. pH modulation of the kinetics of the $\mathrm{Ca}^{2(+)}$ sensitive cross-bridge state transition in mammalian single skeletal muscle fibers. The Journal of Physiology, 1990; 428(1): 751-764. https://doi.org/10.1113/jphysiol.1990.sp018239

28. White AT, Johnson SC. Physiological comparison of international, national and regional alpine skiers. International Journal of Sports Medicine. 1991; 12(4): 374-378. https://doi.org/10.1055/s-2007-1024697

29.Koller A, Schobersberger W. Preseason aerobic and anaerobic tests for prediction of alpine skiing performance: a molecular perspective. BMJ Open Sport \& Exercise Medicine, 2019; 5: e000510. https://doi.org/10.1136/bmjsem-2019-000510

30.Ferland PM, Comtois AS. Athletic profile of alpine Ski racers: a systematic review. The Journal of Strength and Conditioning Research, 2018; 32(12), 3574-3583. https://doi.org/10.1519/JSC.0000000000002900

31.Bangsbo J, Mohr M, Poulsen A., Perez-Gomez J, Krustrup P. Training and testing the elite athlete. Journal of Exercise Science and Fitness, 2006; 4(1): 1-14.

32.Beneke R, Pollmann CH, Bleif I, Leithäuser R, Hütler M. How anaerobic is the Wingate Anaerobic Test for humans? EuropeanJournalofAppliedPhysiology,2002;87(4):388-392. https://doi.org/10.1007/s00421-002-0622-4

33.Hydren JR, Volek JS, Maresh CM, Comstock BA, Kraemer WJ. Review of strength and conditioning for alpine ski racing. Strength and Conditioning Journal, 2013; 35(1):10-28. https://doi.org/10.1519/SSC.0b013e31828238be

34.Korkmaz Ery1lmaz S, Polat M. A comparison of isocapnic buffering phase of cross-country skiers and alpine skiers. Pedagogics, Psychology, Medical-Biological Problems of Physical Training and Sports, 2018; 22(4): 203-209. https://doi.org/10.15561/18189172.2018.0406

35.Edge J, Bishop D, Goodman C. The effects of training intensity on muscle buffer capacity in females. European Journal of Applied Physiology, 2006; 96(1): 97-105. https://doi.org/10.1007/s00421-005-0068-6

36.Erylmaz SK, Kaynak K, Polat M, Aydoğan S. Effects of repeated sprint training on isocapnic buffering phase in volleyball players. Revista Brasileira de Medicina do Esporte, 2018; 24 (4); 286-290. https://doi.org/10.1590/1517-869220182404185842

37.Nakagawa Y, Hattori M. Relationship between muscle buffering capacity and fiber type during anaerobic exercise in human. Journal of Physiological Anthropology and Applied Human Science. 2002; 21: 129-131. https://doi.org/10.2114/jpa.21.129

38. Wade AJ, Marbut MM, and Round JM. Muscle fibre type and aetiology of obesity. The Lancet, 1990; 335(8693): 805-808. https://doi.org/10.1016/0140-6736(90)90933-V

39.Sharp RL, Costill DL, Fink WJ, King DS. Effects of eight weeks of bicycle ergometer sprint training on human muscle buffer capacity. International journal of sports medicine, 1986; 7(01): 13-17. https://doi.org/10.1055/s-2008-1025727

40.Juel C, Klarskov C, Nielsen JJ, Krustrup P, Mohr M, Bangsbo J. Effect of high-intensity intermittent training on lactate and $\mathrm{H}+$ release from human skeletal muscle. American Journal of PhysiologyEndocrinology and Metabolism, 2004; 286(2): E245-51. https://doi.org/10.1152/ajpendo.00303.2003

41.Messonnier L, Denis C, Prieur F, Lacour JR. Are the effects of training on fat metabolism involved in the improvement of performance during high-intensity exercise?. European Journal of Applied Physiology, 2005; 94(4): 434-441. https://doi.org/10.1007/s00421-005-1325-4

\section{Information about the authors:}

Selcen Korkmaz Eryılmaz; (Corresponding Author); http://orcid.org/0000-0002-3680-3580; selcen_korkmaz@yahoo.com; Department of Coaching Education, Faculty of Sport Science, Cukurova University; 01330 Balcalı, Sarıçam. Adana. Turkey.

Metin Polat; http://orcid.org/0000-0001-7299-0531; polat.metin@gmail.com; Department of Physical Education and Sports Teaching, Faculty of Sport Science, Sivas Cumhuriyet University; Kayseri, Turkey.

Cite this article as:

Korkmaz Eryılmaz S, Polat M. Correlation of maximal respiratory exchange ratio with anaerobic power and maximal oxygen uptake in anaerobic trained athletes. Pedagogy of Physical Culture and Sports, 2021;25(4):261-266. https://doi.org/10.15561/26649837.2021.0408

This is an Open Access article distributed under the terms of the Creative Commons Attribution License, which permits unrestricted use, distribution, and reproduction in any medium, provided the original work is properly cited (http://creativecommons.org/licenses/by/4.0/deed.en).

Received: 02.07.2021

Accepted: 25.08.2021; Published: 30.08.2021 